DOCTRINA

\title{
Herramientas del big data y fintech para prevenir y aliviar el sobreendeudamiento del consumidor: Una propuesta
}

\author{
Big data and Fintech tools to prevent and relieve consumer overindebtedness: \\ A proposal
}

\section{Juan Luis Goldenberg Serrano \\ Pontificia Universidad Católica de Chile}

\begin{abstract}
RESUMEN El presente trabajo explora la posibilidad de utilizar las herramientas del big data y del fintech para dar cumplimiento a los deberes de consejo y adecuación, propias del modelo del préstamo responsable, como mecanismos para evitar el endeudamiento excesivo o aliviarlo una vez ocurrido. Con estas formas de procesamiento de información, pueden resolverse ciertos problemas constatados en la dinámica de la regulación tutelar del consumo financiero, como las deficiencias en la configuración de modelos de receptores de la información (el «consumidor medio»), la superación de los deberes de información y su necesaria reformulación como deberes de consejo o de advertencia y las formas de promoción de instancias de renegociación de la deuda para el ajuste a las reales posibilidades de pago del deudor.
\end{abstract}

PALABRAS CLAVE Big data, fintech, sobreendeudamiento, personalización de la ley.

ABSTRACT This paper explores the possibility of using Big Data and Fintech tools to comply with the duties of advice and adequacy, typical of the model of the "responsible loans", as mechanisms to avoid excessive debt or alleviate it once evidenced. With these alternatives of information processing, certain problems in the dynamics of the protective regulation for the financial consumer can be solved, such as the deficiencies in the configuration of models of information recipients (the "average consumer"), the overcoming of the duties of information and its necessary reformulation as duties of advice or warning and the promotion of the renegotiation of the debt for its adjustment to the real possibilities of payment of the debtor.

KEYWORDS Big Data, Fintech, overindebtedness, personalized law. 


\section{Introducción}

El camino hacia un acervo informativo personalizado, en el que se toman en consideración las características particulares y la situación puntual del receptor, viene siendo especialmente desarrollado a partir del avance de la tecnología y, específicamente, del big data ${ }^{1}$ como mecanismo de recopilación y procesamiento de ingentes niveles de datos, incluso con capacidad predictiva del comportamiento futuro esperable de los sujetos (Porat y Strahilevitz, 2014: 1.434-1.440). Así, si bien la propia noción de ley se centra en la idea de la generalización, el caudal informativo y la forma de procesamiento que permiten las nuevas tecnologías permitirían una revisión conceptual tendiente hacia su «personalización» (Porat y Strahilevitz, 2014: 1.418). Por ejemplo, en lo que se refiere a la utilización de parámetros generales para la fijación de estándares de conducta del sujeto típico empleado por la norma (como el buen padre de familia) o para la caracterización del sujeto receptor de un cierto caudal informativo (como el consumidor medio).

Como señala Busch (2019: 313-314), la tipificación amplia dispuesta normalmente en los ordenamientos jurídicos se justificaba por los costos que implica un diseño personalizado como el antes mencionado, pero ésos son dilemas propios de una sociedad predigital. En consecuencia, si el fundamento de ciertas formas de generalización reposaba en las dificultades del procesamiento de la información a fin de producir una mayor diferenciación, tal obstáculo puede ser superado por medio de las técnicas modernas de la inteligencia artificial. De este modo, al igual como hoy en día pueden elaborarse algoritmos para propiciar un mayor ajuste entre las ofertas y recomendaciones que recibe el consumidor en diferentes medios digitales, ${ }^{2}$ incluyendo redes sociales, plataformas de compra, comunicaciones directas por medio de correos electrónicos, etcétera (Willis, 2015: 1.320), o para establecer políticas de precios diferenciados por subcategorías de consumidores (Bar-Gill, 2019: 218; Wagner y Eidenmüller, 2019: 585-592), no parece insensato pensar que los proveedores pueden ajustar sus deberes de información, consejo o advertencia a las necesidades y capacidades de los consumidores receptores de dicha información.

Para los efectos de este análisis, sin embargo, no queremos situarnos en todas las posibilidades que estos mecanismos de ajuste permiten, sino tratar en particular en la problemática dada por los deberes informativos que se plantean en el marco de los productos y servicios financieros bajo las lógicas del fintech (financial technology) y, más específicamente, en el contexto de los créditos de consumo. De forma más

1. Para Bruckner (2018: 7), el big data es un conjunto de datos empíricos, como cualquier otro, pero que se caracteriza por tres « $\mathrm{V} »$ : volumen, variedad y velocidad.

2. Sobre el microtargeting a partir de las preferencias idiosincráticas del consumidor, véase Wagner y Eidenmüller (2019: 582). 
particular aún, nos interesa abordar estos avances tecnológicos en lo que se refiere a la prevención y alivio del sobreendeudamiento del consumidor, considerando que los avances en la tecnología de la información han propiciado la reconfiguración de los productos y servicios financieros ofrecidos por las entidades de crédito, facilitando, incluso, su obtención y utilización por vías remotas. No debe olvidarse, en este respecto, que las técnicas del $e$-banking y del $m$-banking responden a las ideas del $u$-commerce, que, utilizando tecnologías de la información, se destacan por las características de ubicuidad (facilidad en el acceso), universalidad (facilidad en el uso), integración (de sistemas) y distintividad (relativo al carácter diferenciado de la información recibida) (Morrison, Pitt y Kietzmann, 2015: 275-276). De lo anterior se deduce que, al tiempo en que cada vez más se utilizan este tipo de plataformas para la solicitud y procesamiento del crédito, el sistema bien puede generar mecanismos para asegurar la conveniencia de la operación o, incluso, para orientarlo a las mejores alternativas, sin necesidad de desplazarse hasta la entidad bancaria y entregando resultados particulares a las consultas del sujeto. Con ello, podría darse mayor cumplimiento a una de las medidas advertidas en el contexto europeo para evitar el sobreendeudamiento, y que, en el marco general del denominado "préstamo responsable», supone que

el comportamiento responsable de los profesionales debe ejercerse ya en las ofertas y la publicidad que difunden, así como en el asesoramiento y las explicaciones que facilitan a los consumidores en el momento de la suscripción de los créditos. Para ello es necesario un enfoque personalizado, por lo que es de lamentar que no sea la práctica habitual en la actualidad, a pesar de la legislación vigente y de los códigos de conducta existentes en la mayoría de los países. ${ }^{3}$

Lo anterior, advirtiendo que los concedentes de crédito pueden tomar en cuenta el historial crediticio y el comportamiento de sus clientes no solo para identificar las necesidades específicas de financiamiento del individuo, o para la fijación más precisa de una tasa de interés u otros términos contractuales que consideren el riesgo particular de cada sujeto de crédito, sino para asesorar al consumidor sobre la conveniencia o no de obtener un determinado producto - o compararlo con las ventajas y desventajas con otro, a fin de promover su adecuación al perfil del cliente- $y$, en los casos más extremos, anticipar también situaciones de riesgo de sobreendeudamiento $y$, eventualmente, de insolvencia, lo que propicia modelos predictivos que permitan tomar a tiempo medidas preventivas o resolutivas, como la renegociación de la deuda. El asunto se presenta precisamente por la obtención de dicha información

3. Dictamen del Comité Económico y Social Europeo sobre «Protección de los consumidores y tratamiento adecuado del sobreendeudamiento para evitar la exclusión social», dictamen exploratorio 2014/C, 311/o6, disponible en http://bit.ly/2qZGtHF. 
personalizada, que permite, asimismo, distinguir perfiles de sujetos en atención a sus posibilidades de comprensión de los términos económicos y jurídicos de la operación, en la primera fase, o generar sistemas de alerta, en la segunda. Así, en la medida en que el proveedor puede diferenciar a uno y otro sujeto, bien puede ofrecer un producto que resulte más riesgoso para un grupo de individuos con mayores niveles de información y racionalidad, y productos más seguros y estables para quienes no gozan de iguales cualidades (Bar-Gill y Warren, 2008: 22). Asimismo, podrá utilizarse la misma información, unida al comportamiento del sujeto, para la modificación de la cartera de créditos hacia productos más adecuados en los casos en que se observe un cambio en el patrón de conductas que amerite llevar a cabo la renegociación de la deuda a efectos de evitar incumplimientos, morosidades o insolvencia.

La hipótesis con la que trabajamos es que estas herramientas tecnológicas, que disminuyen los costos de la formación y transmisión del consejo y de la advertencia al consumidor vulnerable, constituyen mecanismos idóneos para que las entidades crediticias puedan predecir con más precisión los riesgos de sobreendeudamiento, comunicarlos de manera adecuada al consumidor financiero e, incluso, ofrecer mecanismos de alivio una vez éste se encuentre en el área de la insolvencia y del sobreendeudamiento. Nuestro objetivo es revisar las variables jurídicas a considerar para la formulación de estos instrumentos, para lo cual se analizará, en primer término, la posibilidad de reemplazar el modelo del «consumidor medio» por uno que se ajuste a la realidad de cada uno de los consumidores, de forma tal que, a partir de ciertas herramientas tecnológicas, puedan generarse consejos, advertencias y adecuaciones moduladas a partir de la vulnerabilidad financiera de los sujetos. Luego, se abordará la problemática de los costos implícitos en la implementación de estas herramientas a partir de la discusión de su consideración como reglas supletorias, imperativas o imperativas de mínimos; y, por último, se ofrecerán parámetros generales para advertir la existencia del riesgo de sobreendeudamiento, y, según ellos, poder diseñar mecanismos de alerta para la identificación de los niveles de vulnerabilidad financiera. Todo ello para terminar con las conclusiones de rigor.

\section{El reemplazo del paradigma del consumidor medio para fines de información, consejo y advertencia}

A grandes rasgos, la dotación de información general —o impersonal— relativa a las características generales de un determinado producto o servicio financiero (crédito de consumo, líneas de crédito, tarjetas de crédito, avance en efectivo u otros), podrá resultar insuficiente, si no lisa y llanamente omitida por el receptor, en atención a los múltiples sesgos cognitivos identificados por medio de los estudios de la economía conductual (Andrade Ramírez, 2013; De la Maza Gazmuri, 2010; Goldenberg Serrano, 2017). Asimismo, se constata que los consumidores financieros, en tanto categoría 
heterogénea únicamente identificada por tratarse de un beneficiario final de un producto o servicio (artículo 3.2 del Decreto Supremo 43/2012, del Ministerio de Economía), pueden poseer diversas capacidades y conocimientos (Sheff, 2013: 480-481), de forma que, aun en el caso de ser superados esos sesgos, la problemática se sitúa en su comprensión y utilización para la adopción de la decisión de endeudamiento. De ahí que, en cualquier caso, los costos de la producción, tratamiento y entrega de la información asimétricamente distribuida, como su eventual particularización en atención a las características puntuales del receptor, se aprecia como una técnica sumida en una variedad de costos (Vandenberghe, 2011: 46-48), propiciándose, entonces, por una estandarización fundada en criterios meramente económicos.

En este sentido, estos deberes generales pueden ser reemplazados por técnicas más eficaces, si acaso se quiere mantener el «paradigma de la información» como sustrato del derecho de consumo. ${ }^{4}$ El punto de partida se encuentra en desgajar de este paradigma el modelo único del consumidor medio que, en nuestro entorno, se ha desarrollado especialmente en el campo del derecho marcario y de la competencia desleal, al extremo que el Tribunal de Defensa de la Libre Competencia lo ha identificado como «un consumidor razonablemente informado, atento y perspicaz», que valora en torno a parámetros de «tiempo, de conocimiento y de medios» para apreciar la información recibida. ${ }^{5}$ Estas nociones pueden rastrearse hasta la construcción del derecho del consumo europeo, ${ }^{6}$ de manera que se asume que este consumidor modelo podrá superar los problemas que devienen de la asimetría informativa una vez cumplidos los deberes de información por parte del proveedor, lo que resuelve el fallo de mercado que implica su carencia de información (Rojas Covarrubias, 2015: 418), como también deslinda un estándar de responsabilidad, al requerir un comportamiento diligente del consumidor que sale en su búsqueda, aunque debe subrayarse la existencia de una relación de dependencia entre esta segunda suposición y el primero.?

4. Sobre las dificultades del perfeccionamiento de la protección del consumidor sobre la base de los deberes de información desde la perspectiva de la economía conductual, véase Bubb y Pibles (2014: 1.647-1.658), y para una formulación crítica general, Ben-Shahar y Schneider (2011) y De la Maza Gazmuri (2010).

5. Sentencia del Tribunal de Defensa de la Libre Competencia, rol C-151-2008, 8 de septiembre de 2010.

6. Caso C-210/96 Gut Springenheide and Rudolf Tusky con Oberkreisdirektor des Kreises Steinfurt, ECR I-4657, 1998, con igual referencia en el considerando 18 de la Directiva 2005/29/CE del Parlamento Europeo y del Consejo, del 11 de mayo de 2005, relativa a las prácticas comerciales desleales de las empresas en sus relaciones con los consumidores en el mercado interior.

7. Sentencia de la Corte de Apelaciones de Santiago, rol 1535-2014, del 24 de marzo de 2015, que resolvió que: «El primero [el proveedor] debía informar y el segundo [el consumidor] informarse, mas éste obviamente obtiene la información necesaria del primero, que tiene y conoce o debe conocer toda la información, mas la omite en lo relativo a aquella parte relativa a la validación». 
Este desgaje supone como alternativa la posibilidad de entrega de información más específica - por ejemplo, a modo de consejo personalizado, como sugiere Busch (2016: 234), preferible a la sola entrega de datos-, lo que antes requiere de la estratificación de los clientes en consideración a su situación personal y, en lo que nos interesa, en sus índices de vulnerabilidad. Podrá observarse que la identificación del «consumidor financieramente vulnerable» sigue importando algún nivel de generalización, aunque una caracterización todavía más específica advierte que existe un punto en el que el costo de la diferenciación supera a las ventajas que pueden deducirse de ella. Así, del mismo modo en que los algoritmos suponen, bajo ciertos parámetros, que el cliente podría ser tentado con un determinado producto por medio de avisos en las plataformas digitales, un ajuste en extremo particular supondría conocer detalles de la vida personal del sujeto, incluso más allá de su interacción con la mentada plataforma ${ }^{8}$ o de su relación previa con el proveedor financiero. Si bien es cierto que el tratamiento de la información financiera de los consumidores es aún un tema pendiente de desarrollo en nuestro entorno, ${ }^{9}$ la construcción de esta solución puede pasar, al menos, por la revisión de la información interna con la que ya cuenta la entidad financiera, ${ }^{10} \mathrm{a}$ fin de detectar los patrones de ingresos, gastos y morosidades, como asimismo aquellos comportamientos que son propios de quien se encuentra en fases cercanas a una crisis patrimonial. Para estos efectos, tomando los conceptos ofrecidos por Bar-Gill (2012: 35), es posible configurar tal información a partir de criterios estadísticos generales o de la información particular con la que cuenta la entidad, a efectos de considerar los patrones de uso de un determinado producto o servicio financiero, sobre todo si se considera que éstos normalmente se configuran sobre la base de relaciones a largo plazo que precisamente permiten la recolección de información particularizada. Así, por ejemplo, se ejemplifica sobre la base de los detalles de cada una de las operaciones ejecutadas (lugar, tiempo, monto, proveedor) en contraste con la información que se posee sobre el propio cliente (nombre, índices de solvencia, dirección, tiempos de pago), en especial si éste tiende a consolidar sus productos y servicios en una misma entidad financiera (Bar-Gill y Warren, 2008: 23).

Fuera de estos casos, el costo de obtención de la información más precisa podría

8. Porat y Strahilevitz (2014: 1.433 y 1.434), respecto de las diferencias entre las reglas supletorias (default rules) crudas y granulares, estas últimas siendo las que toman en consideración los comportamientos pasados del sujeto que permiten una proyección sobre sus decisiones futuras.

9. Para esto vale la pena revisar la difícil tramitación del proyecto de ley que regula el tratamiento de la información sobre obligaciones de carácter financiero o crediticio (Boletín 7886-03), aunque parecen asomarse tiempos de avance, en especial si se considera el cambio de postura del retail financiero ahora que la mayor parte del negocio ha sido adquirido por las entidades financieras.

10. El proceso de data mining en la propia industria financiera, con el impresionante caudal de datos históricos de los clientes, parece indispensable para efectuar la mentada proyección. Sobre este particular, Schutte (2017). 
parecer excesivo - por ejemplo, en la composición de ingresos y gastos de su grupo familiar, las razones laborales, familiares o médicas que pueden haber conducido al sobreendeudamiento, etcétera-, sobre todo si el problema no se centra en sus preferencias, sino en percepciones erróneas (Bar-Gill, 2019: 219-220), que no siempre son plenamente diferenciables. Sin perjuicio de lo anterior, como parte relevante de la industria del fintech, se han ido generando plataformas de asesoramiento automatizado (robo-consejeros o robo-advisors) basado en los perfiles de riesgo, antecedentes y metas de los clientes (Jannarone, 2018: 154). Su significado genérico es la entrega del consejo financiero por medio de una plataforma digital (Degeling y Hudson, 2018: 63) y su operatividad se basa en: i) la recolección de datos de manera voluntaria entregados por parte de los clientes -incluyendo toda suerte de datos personales, incluso sensibles—,, justificables bajo los parámetros de la «autogestión de la privacidad» (Solove, 2013); y ii) en la información obtenida por medio de las respuestas a las múltiples preguntas dispuestas por la plataforma (Degeling y Hudson, 2018: 66; Edwards, 2018: 98), los que son utilizados por los algoritmos de la entidad financiera para generar el consejo de endeudamiento o inversión adecuado (Ausley, 2019: 93). Más extremo aún, los préstamos basados en algoritmos (algorithmic lenders) suponen el uso de big data para la calificación de solvencia de manera supuestamente más rápida, barata y predictiva que los sistemas habituales de credit-scoring (Bruckner, 2018: 5), aunque utilizando métodos no tradicionales de cálculo, que pueden incluir «las direcciones de correo electrónico, la marca del automóvil, las amistades de Facebook, los antecedentes educativos» y más (Bruckner, 2018: 15). Sin embargo, en ambos casos, con mayor o menor magnitud, se revelan problemas de protección de datos (Ausley, 2019) ${ }^{12} \mathrm{y}$ de eventuales formas de discriminación, sobre todo al utilizar categoría sospechosas o proxys para llegar a ellas (Bruckner, 2018; Gillis y Spiess, 2019).

Superados de manera adecuada estos cuestionamientos preliminares, la principal preocupación atendería a fijar el contenido preciso de la información otorgada o de la actitud esperable por parte del concedente del crédito una vez concluido el proceso y advertido un cierto nivel de riesgo apreciable en el solicitante de crédito. Una alternativa es simplemente propiciar un cierto deber de alerta $^{13} \mathrm{u}$ obligación de advertencia, ${ }^{14}$

11. Jannarone (2018: 153) destaca que, en este punto, los robo-consultores no se distinguen de manera sustancial en su operativa de los asesores financieros tradicionales. La diferencia se produce, en consecuencia, en la forma de procesamiento de los datos y las decisiones obtenidas por medio del uso de los algoritmos.

12. En nuestro entorno, problemas que son maximizados con la incorporación del principio de finalidad para el tratamiento de los datos por parte de la Ley 20.575, de 2012.

13. En Goldenberg Serrano (2018: 21) se destaca que su «finalidad es destacar de modo más patente los elementos negativos o eventualmente nocivos o perjudiciales que pueden derivarse de la contratación». 14. López Díaz (2018: 277-278) califica como «más exigentes que las obligaciones de información, pues 
cuyo contenido informativo se sitúa en la mera indicación de los nocivos efectos que podría tener para el consumidor tomar una nueva decisión de endeudamiento en atención a su estado patrimonial actual, ${ }^{15} \mathrm{O}$ conducirlo, por medio del establecimiento de deberes de asesoramiento o consejo (Goldenberg Serrano, 2018), a la posibilidad de renegociación de la deuda total para anticipar una situación de mayor riesgo (consolidación de la deuda o debt consolidation); otra, es elaborar los contornos de una suerte de deber fiduciario de la entidad financiera a favor del consumidor que le impida contratar dicho producto o servicio financiero, "por el bien de su cliente», o directamente activar alguna suerte de renegociación automática de los términos de los créditos vigentes para adecuarla al nuevo perfil de riesgo.

Ambos extremos nos parecen incorrectos, ya sea por defecto o por exceso. El primero, porque la sola advertencia difícilmente podría aplacar la problemática financiera en la que ya se encuentra el consumidor, quien probablemente advierte que la nueva contratación de crédito es una solución que alivia solo de manera temporal sus necesidades financieras, pero que es probable que solo postergará el punto de no retorno. Lo anterior se atisba como una grave problemática en el sistema crediticio nacional, como se observa en la Encuesta Financiera de Hogares 2017 del Banco Central. Así, en referencia a las motivaciones de todas las clases de deudas no hipotecarias ponderadas en cuanto a su monto, la citada encuesta señala que ellas se ordenan, en primer lugar, a cancelar otras deudas - por medio de deuda en casas comerciales, créditos bancarios, de cajas de compensación y cooperativas, automotriz, educacional e incluso préstamos informales - y luego al financiamiento de gastos educacionales. Además, excluyendo los créditos automotrices y educacionales, las principales motivaciones del endeudamiento por medio de tarjetas de crédito bancarias y o bancarias, ponderados por monto, son la compra de artículos durables para el hogar $(18,4 \%)$ y la cancelación de otras deudas $(11,8 \%)$. Lo anterior se condice con el creciente número de personas que presentan morosidades con el sistema financiero que, conforme al 24..$^{\circ}$ Informe de Deuda Morosa (primer trimestre de 2019) preparado por la Universidad San Sebastián y Equifax, se estima en el orden de 4.604.770 sobre un universo de alrededor de once millones de deudores.

La segunda solución tampoco parece adecuada porque una intervención tal supone un paternalismo extremo (García Porras y van Boom, 2012: 25), que termina privando de autonomía y de poder decisorio a quien, en términos generales, mantiene

el deudor debe proporcionar una información objetiva, precisando el riesgo o peligro que se derivará de desestimarla, antecedente que permitirá al acreedor decidir si resulta conveniente contratar».

15. En términos generales, aunque todavía dudando de la eficiencia de los deberes de información, Wagner y Eidenmüller (2019: 596) proponen una advertencia o «notificación visceral», por ejemplo, en forma de avatar que aparece en la pantalla del consumidor y busca en internet bajo las condiciones de una vulnerabilidad aguda. 
intocable su capacidad jurídica. Además, la conservación —aunque matizada- del paradigma de la información como sustento de protección supone el reconocimiento de la autonomía del consumidor quien, al contar con información -en este caso, diversificada-, se encuentra en posición de tomar una mejor decisión (Sheff, 2013: 476). Aunque sí encontramos en nuestro ordenamiento ejemplos de limitaciones a la posibilidad de endeudamiento en situaciones de vulnerabilidad, ${ }^{16}$ estas reacciones normativas deben ser tomadas con extrema cautela, porque una ampliación exagerada termina por infantilizar a los consumidores, privándoles de la autonomía que configura una de las bases de nuestro ordenamiento jurídico. Por su parte, la renegociación automática, por no decir unilateral, ya se ha detectado como una conducta abusiva por parte de las entidades crediticias que, más que atender a las necesidades del cliente, se sitúan en la búsqueda de un blanqueamiento de los estados financieros (como se apreció en el caso La Polar).

Una opción intermedia se encuentra en conducir al cliente a tomar decisiones más racionales que las que, en los hechos, puede considerar de manera aislada a partir de su situación de vulnerabilidad financiera. Aquí, siguiendo la distinción efectuada por Bar-Gill (2012: 33-36), conviene precisar que la información no debería detenerse en aquellos aspectos que se refieren a los atributos particulares de los productos financieros disponibles (como la tasa de interés, los costos del producto o las condiciones generales de pago), sino en los que se refieren al uso del producto, como «los patrones de préstamo y la incidencia de la mora». Los primeros aspectos, si bien necesarios para la decisión de endeudamiento ( $\mathrm{y}$ a los que apuntan estrategias de simplificación informativa como la de la «carga anual equivalente» o CAE) (Baquero Herrera y Caballero Germain, 2013), no resultan suficientes para ofrecer soluciones más adecuadas al cliente vulnerable, sino en cuanto ellas puedan enlazarse con las conductas relativas al uso del producto en atención a la propia vulnerabilidad. Ahora bien, aun cuando es posible considerar que, respecto de esta dimensión, es el cliente quien normalmente se encuentra en mejor posición de conocer de manera anticipada tal uso o destino (Bar-Gill, 2012: 34), no es menos cierto que el avance de las tecnologías de la información puede otorgar poderosas señales al concedente del crédito que le permiten actuar, aun en ausencia de tal indicación, para incitar una determinada conducta por parte del consumidor en problemas. Adviértase que, en el

16. Con carácter absoluto, encontramos la prohibición de otorgamiento de crédito a los jugadores por parte de los operadores de casinos de juego (Ley 19.995, artículo 7), caso en el cual la vulnerabilidad derivaría de la especial situación en la que se encontraría el jugador que requiere, en el impulso de la jornada de apuestas, de fondos de los que carece; y, con carácter relativo, la Circular 3.093, de la Superintendencia de Seguridad Social, que establece límites de endeudamiento por medio de créditos sociales para pensionados con pensiones básicas solidarias u otras de igual o inferior monto, en los que la vulnerabilidad es claramente financiera. 
extremo propuesto por Wagner y Eidenmüller (2019: 582), los proveedores conocen al menos lo mismo que los consumidores saben sobre sí mismos, y, en oportunidades, incluso más, en especial en lo que se refiere a aspectos que pueden encontrarse nublados por sesgos cognitivos.

Nuevamente en el orden del funcionamiento de los robo-consultores, y siguiendo en esto a Degeling y Hudson (2019: 64-65), éste se despliega en dos órdenes de consejo. El primero funciona a modo de «consejo sobre consejo» (advice about advice), en que el sistema funciona como un custodio (gatekeeper) para ponderar si el perfil del cliente admite la asesoría misma o, en su caso, el tipo de asesoría o de productos al que está destinado. En esta órbita, el sistema debe detectar el nivel de asimetría informativa y vulnerabilidad del cliente (Ben-Shahar y Porat, 2019: 274), de manera de promover un modelo informativo realmente ajustado a sus necesidades y, solo una vez logrado lo anterior, pasar a un escalón superior. Con ello, se aliviaría el problema detectado por Sheff (2013: 485) sobre establecer un punto en el continuo de las capacidades que separa a los ingenuos de los sofisticados. Así, recién en la segunda fase de asesoría, ahora sustantiva (substantive advice), se situaría al cliente en un árbol de decisiones (decision tree) que lo haría transitar por sus diversas ramas hasta encontrar el producto o servicio financiero que resulta más adecuado a su perfil, intereses y necesidades, bajo la fórmula de los deberes de adecuación alentados por la International Financial Consumer Protection Organization (Finconet, 2019: 15). La disposición de dichas ramas y las rutas por las que el cliente transita pueden estar previamente configurados por el proveedor en algoritmos más básicos (dumb algorithms) (Bruckner, 2018: 9) o, en versiones más avanzadas, reconfigurados una y otra vez por medio del aprendizaje obtenido de los procesos de consulta anteriores para mejorar la predicción (learned algorithms $),{ }^{17}$ los que en cualquier caso son construidos a partir de la información del que se va alimentando el sistema y del que se derivan los diversos filtros operativos. En lo que nos interesa, un modelo como el anterior puede ser replicado no solo para efectos del ofrecimiento de un portafolio de inversión adecuado, sino para revisar el perfil de vulnerabilidad del sujeto al tiempo de la solicitud de crédito. De nuevo a modo de gatekeeper, la detección temprana de un riesgo más extremo derivaría en el filtro completo del sistema, sin admitir siquiera el paso a un consejo sustantivo, sino solo la generación de una alerta que se adecúe al derecho de todo consumidor financiero a conocer la negativa de la contratación por razones objetivas (artículo 3, inciso segundo 2, letra a de la Ley 19.496, y artículos 19 a 21 del Decreto Supremo 43/2012, del Ministerio de Economía) o que lo conduzca a dinámicas de renegociación de la deuda para provocar el ajuste a su perfil de vulnerabilidad financiera.

17. Bruckner (2018: 16) señala que el principal problema de estos últimos es que, dado su propio mecanismo de aprendizaje, crean un problema de caja negra en que se oscurece la posibilidad de entender el resultado y auditar si en éste se han utilizado variables discriminatorias. 
Superado dicho escollo, niveles medios de vulnerabilidad deberían conducir al sujeto a un árbol de decisiones que lo haga transitar hacia productos o servicios financieros más convenientes, no solo en la tasa, sino en cuanto a las formas y condiciones de pago, y lo aleje de aquéllos que sean más peligrosos debido a su estado patrimonial. En este sentido, un paternalismo suave, como el que se propone a partir de la técnica de los nudges, implica, por ejemplo, evitar el ofrecimiento de productos y servicios financieros que puedan ahondar en la crisis e incitarlo a la contratación de aquellos que producen menor mella, si no un alivio, en su situación patrimonial. Ello se deriva del hecho de que, en contextos de competencia imperfecta como los que suponen los mercados del crédito al consumo, la indagación de alternativas más económicas se dificulta, sobre todo en caso de productos y servicios más complejos (Bubb y Pildes, 2014: 1.639-1.642), con clientes con escasos conocimientos financieros (Jannarone, 2018: 143), y en escenarios en los que el consumidor sobreendeudado probablemente tomará decisiones más impulsivas con motivo de un exacerbado present-bias o miopía (Bar-Gill, 2012: 83-87; Meier y Sprenger, 2010).

Todo lo anterior, alertando que existe más preocupación por los estándares de seguridad en el campo de los productos y servicios físicos, mientras que el problema se presenta en el campo del mercado crediticio, en que el riesgo (sobreendeudamiento, embargos, insolvencia, etcétera) no parece sujeto a igual escrutinio por parte del legislador, admitiendo una complejidad creciente en los términos y condiciones contractuales que terminan por situar al deudor en una posición de extrema ignorancia (Bar-Gill y Warren, 2008: 3-5). De ahí que resulte conveniente el establecimiento de ciertos deberes de advertencia respecto de los productos especialmente riesgosos desde el punto de vista patrimonial, como se sugiere, por ejemplo, en la guía de la International Financial Consumer Protection Organization, que promueve el establecimiento de alertas relativas al costo, a los riesgos asociados al vencimiento a corto plazo y a los riesgos y consecuencias del sobreendeudamiento, al tratar de los préstamos por montos menores sujetos a altas tasas, hoy en día con frecuencia ofrecidos por medios digitales (Finconet, 2019: 12).

En este punto, de modo similar al funcionamiento de los algoritmos que toman en consideración factores idiosincráticos del consumidor para la provocación del mayor consumo, el modelo podría ser utilizado en una faceta inversa, en la que se le aleja de los productos que le pueden resultar más nocivos a pesar de su disponibilidad, e incitarlo a elegir otras vías que resulten más apropiadas a sus circunstancias actuales. Aun cuando podría pensarse que tales soluciones son contraintuitivas para una entidad financiera cuyo motor principal es el lucro, no debe dejarse de considerar que la insolvencia del deudor constituye un escenario indeseable para cualquier acreedor. Lo anterior, en especial en el ordenamiento nacional, en el que tal situación patrimonial, conducida por medio de un procedimiento concursal, puede terminar derivando en la extinción legal de los saldos insolutos de las obligaciones (artículos 255 y 268 
de la Ley 20.720, de 2014) (Alarcón Cañuta, 2018; Caballero Germain, 2018), y, por tanto, no solo en la pérdida de la ganancia esperada, sino de enfrentar un escenario en que todo el crédito resulta impago. El problema se presenta, no obstante, porque la entrega de información que se sustente en el ofrecimiento de caminos más seguros para el consumidor, basado en las dinámicas habituales del uso del producto o servicio financiero, podría implicar que se abstenga lisa y llanamente de consumir —en el caso de poder hacerlo- o que, a partir de tal información, busque alternativas más atractivas en la competencia. De ahí la necesidad de ponderar - si acaso se plantea un deber de información como el propuesto- si debe formularse bajo la lógica de un requerimiento legal obligatorio, o si acaso aún puede dejarse en el marco de la autonomía y la solución puramente de mercado ${ }^{18}$ cuestión que se abordará en el siguiente apartado.

A nivel comparado, el ordenamiento alemán incorporó en 2016 un deber informativo especial por parte de los bancos respecto de los consumidores financieramente vulnerables, en particular en lo que respecta a la utilización de las líneas de sobregiro (\$504(1) BGB). ${ }^{19}$ Tal medida obedece a la comprensión de que se trata este de un producto financiero comparativamente más oneroso, de modo que el banco debe prestar la asesoría necesaria para conducirlo a alternativas más baratas, a ponerlo en conocimiento de las consecuencias negativas derivadas del sobregiro y las alternativas de consultoría en caso de encontrarse ante una crisis más profunda (Busch, 2019: 317-318). En el ordenamiento chileno, tal posibilidad no parece ajena a las preocupaciones del legislador, aunque con un tono bastante menor. De este modo puede comprenderse, por ejemplo, la reforma del artículo 37 de la Ley de Protección del Consumidor por medio de la Ley 21.062, de 2018, que incorporó ciertos deberes adicionales de información que deben llevar a cabo las empresas de cobranza extrajudicial y los proveedores de créditos que efectúen procesos de cobro, al iniciar cualquier gestión destinada a la obtención del pago de la deuda. Al efecto, la indicación de «la posibilidad de pagar la obligación adeudada o las modalidades

18. Como indica Bar-Gill (2012: 35), las razones por las cuales debe imponerse el deber informativo - si pudiese suponerse que el proveedor podría estar dispuesto a cumplirlo de manera voluntaria-, se debe a que no siempre es efectiva tal voluntariedad, en especial en el caso de información relativa al uso de los productos.

19. La citada norma dispone lo siguiente: «1) Si se otorga un préstamo al consumidor en el contexto de una relación contractual de cuenta corriente en que el prestatario tiene el derecho a sobregirar su cuenta hasta un monto específico (sobregiro), el prestamista debe proporcionarle al prestatario, en intervalos regulares, la información establecida en el artículo 247, sección 16, de la Ley de Introducción al Código Civil [Einführungsgesetz zum Bürgerlichen Gesetzbuche]. No tiene aplicación el derecho a indemnización por el reembolso anticipado del préstamo conforme a la sección 502. La Sección 493 (3) solo se aplica en caso de un aumento en la tasa de préstamo y se aplica, con las modificaciones necesarias, a un aumento en los otros costos que se han acordado. La sección 499 (1) no tiene aplicación» (traducción del autor). 
de pago que se ofrezcan», presupone, al menos como segunda alternativa, el ofrecimiento de modalidades de pago diferentes a las inicialmente convenidas, lo que tendría lugar en los casos en los que ya se ha evidenciado una situación de morosidad que amerita el inicio de las gestiones de cobranza. Ahora bien, si pensamos cómo puede darse dicho ofrecimiento de manera adecuada y eficiente, la opción que se propone es hacer uso de la inteligencia artificial, conducida sobre la base de algoritmos, que adecúe el calendario a las capacidades de pago del cliente moroso. Así, en la guía de la International Financial Consumer Protection Organization también se agregan recomendaciones para incluir mecanismos de detección de dificultades de pago, de manera de poder brindar apoyo y consejo a los consumidores en situación de riesgo (Finconet, 2019: 16).

\section{Una explicación a partir de los costos: El deber de información como regla supletoria y el problema del subsidio cruzado}

En el contexto del derecho contractual, la función de las reglas supletorias (default rules) se ha identificado, al menos desde la perspectiva económica, con la limitación de los costos de transacción (Wagner, 2011: 16). La eficiencia de la regla supletoria, en consecuencia, se mide a partir de las oportunidades en las que los actores del mercado deben alterarla o matizarla, previa negociación, para ajustarla a sus necesidades particulares. De tal suerte, si los agentes en su mayoría deben alterar o matizar la regla, resulta que ella incumple su propósito económico y, en consecuencia, debería ser revisada para facilitar el intercambio sobre la base de una negociación hipotética que aquellos llevarían normalmente a cabo (hypothetical bargain) (Porat y Strahilevitz, 2014: 1.425). Aquí, sin embargo, el punto se encuentra también en la identificación de las bondades de una u otra regla supletoria, no solo desde la perspectiva de dicha eficiencia, sino también del comportamiento que se espera de parte sus receptores, con una significación basada en la idea de un canonical nudge, que alienta una determinada conducta, aun cuando, con mayor o menor dificultad, también admite su alteración (opt-out) (Sunstein, 2013: 5). En la materia que nos interesa, claro ejemplo de lo anterior se encuentra en la reciente reforma del Decreto con Fuerza de Ley 707, de 1982 (ley de cuentas corrientes bancarias y cheques) por parte de la Ley 21.167, de 2019, en que se dispone que el pago del crédito que se haya estipulado para la cuenta corriente bancaria será automático, con los abonos que se hagan a la cuenta corriente correspondiente, siempre y cuando no exista deuda vigente por créditos no estipulados; sin perjuicio de que el cuentacorrentista puede efectuar pagos por otras vías (en sucursal o por transferencias), y, a modo de opt-out, instruyendo al banco de manera expresa y voluntaria que el pago no se haga de manera automática. Con ello, se logra facilitar el pago de un tipo de crédito que resulta bastante más oneroso para el consumidor financiero, pues se evita el devengo de intereses por retardo en su pago, aun 
cuando se deja un espacio de autonomía para la modificación de la regla, aunque solo a favor del consumidor. ${ }^{20}$

No obstante, esta valoración económica solo tiene lugar en el campo de las normas dispositivas, por cuanto las reglas imperativas (ius cogens) no admiten tal variación. En este supuesto, no es posible ponderar la eficiencia de la regla sobre la base de la frecuencia en la que los sujetos la alteran, precisamente porque la norma no resulta modificable sin incurrir en un fraude a la ley. Asimismo, dado que en nuestro sistema dichas normas deben apreciarse como excepcionales en el juego del derecho de los contratos, su formulación, al menos en el ámbito del consumo, se escuda en la finalidad tuitiva que se desprende de la asimetría existente entre las partes, como un mecanismo de protección configurado a favor de quien no puede protegerse por sí mismo, ni convenientemente de sí mismo (Ayres y Gertner, 1989: 88). Por ello, al menos desde la perspectiva económica, se espera que los resultados de la intervención legislativa en el contrato sean igual de eficientes, pero ahora matizados en torno a la satisfacción de los propósitos tutelares del ordenamiento.

Algún matiz debe efectuarse respecto a las normas «imperativas de mínimos», en que se admite un campo de acción a la autonomía privada, pero solo si se ofrecen alteraciones en beneficio de la parte estructuralmente débil. Por ello, también se les llama «normas unilateralmente obligatorias» (Wagner, 2011: 11). Nos interesa el punto porque ello es justo lo que ocurre con los deberes de información que se disponen en la órbita del consumo y sobre todo en la del consumo financiero. ${ }^{21}$ Así, aun cuando las partes podrían estar dispuestas a negociar menores deberes por parte de la entidad financiera, por ejemplo, por el conocimiento financiero que ostenta el cliente $-\mathrm{y}$, por tanto, la innecesaridad de simplificación o del hecho mismo de su otorgamiento-, el ordenamiento tutelar impedirá tal negociación. Ello hace suponer que el estándar mínimo ofrecido por la ley se estima que es el realmente conducente a la satisfacción general de la finalidad protectora de la norma, sobre la base de una generalización

20. En este sentido se expresó el senador Coloma, como uno de los autores de la moción: «Agregó que el problema se produce porque, si un cuentacorrentista se sobregira utilizando el cupo de la línea de crédito y, posteriormente, recibe fondos que permitirían saldar la deuda de dicha línea, el banco no efectúa automáticamente el abono, y los fondos quedan en la cuenta corriente, mientras la deuda del sobregiro sigue generando altos intereses. Manifestó que, desde una perspectiva de la conveniencia del deudor cuentacorrentista, lo razonable es que al existir fondos abonados en la cuenta corriente, la obligación del banco sea pagar todo o parte del sobregiro pactado utilizado» (Historia de la Ley 21.119, Informe de la Comisión de Hacienda del Senado, 9 de abril de 2019).

21. La persistencia de esta clase de deberes, a pesar de la argumentación en torno a su eficiencia, se encuentra en que se trata del «la forma de regulación menos intrusiva y, en consecuencia, la forma de regulación que más probablemente será adoptada. Adicionalmente es porque los mandatos de información, cuando han sido diseñados óptimamente, apuntan directamente a los errores y falsas percepciones en el centro de los fallos conductuales de mercado» (Bar-Gill, 2012: 32) (traducción del autor). 
sustentada en dos supuestos previos: por una parte, la formulación de la asimetría de las partes desde la idea de la ignorancia o de los costos del conocimiento; y, por la otra, el establecimiento de un contenido informativo típico sobre la base de un consumidor medio. Por otro lado, si las partes están dispuestas a incrementar el estándar informativo - sea en cantidad o en calidad-, incluso por medio de un sobrecosto del producto o servicio financiero, el ordenamiento no pondrá obstáculos a dicha posibilidad en la medida en que la propia protección del consumidor se ha establecido, entre otros, sobre los pilares que propician las medidas que limitan las asimetrías informativas. Así, aun cuando el legislador lo considere en general innecesario para la finalidad de protección propuesta, no advierte inconvenientes en que, tomando en cuenta ciertas circunstancias fácticas consideradas en la negociación, pueda establecerse una regla aún más beneficiosa, al igual como ocurre en la dinámica de las reglas supletorias.

Ahora bien, en el contexto que nos preocupa, tales posibilidades no resultarán adecuadas para justificar la eficiencia del resultado, tanto desde la perspectiva de la limitación de los costos de transacción — según ocurre con las reglas supletorias-, como respecto de la satisfacción del estándar de protección de la parte débil —según ocurre con las normas imperativas-. Al efecto, el consumidor que se encuentra en la posibilidad de pagar por mecanismos informativos más específicos a su situación financiera, o bien no se encuentra en una situación patrimonial crítica, o solo la avizora como una posibilidad lejana. Al contrario, el consumidor que ya se encuentra en una situación de crisis - o al menos al borde de ella-, probablemente no tendría los recursos financieros suficientes para dedicarlos a la obtención de mejores estándares informativos, o incluso una asesoría financiera personalizada. Lo anterior, además de los sesgos cognitivos que podrían impedirle apreciar la extensión y profundidad de la crisis que le afecta o acecha. ${ }^{22} \mathrm{Al}$ ser así, los estándares informativos medios, estructurados sobre la base de una generalización de la homogeneidad de los consumidores financieros, causan resultados ineficientes en lo que se refiere a la información necesaria para enfrentar un contexto de crisis. ${ }^{23}$ Quien no la requiere estaría pagando por el procesamiento la obtención de información estandarizada que se le presenta inútil

22. Sobre los sesgos cognitivos en materia de sobreendeudamiento, véase Goldenberg Serrano (2017).

23. Como señala Sunstein (2014: 8), «la mayor parte de las reglas supletorias son impersonales, en el sentido de que ellas no distinguen entre los miembros de los grandes grupos en los que ellas se aplican. Las reglas supletorias impersonales pueden ser escogidas por múltiples razones. Quizás no existen diferencias relevantes entre los miembros del grupo afectado por tales reglas, y consecuentemente, la impersonalización no es perjudicial; las reglas personalizadas no tendrían sentido. Quizás los arquitectos de la elección carecen de la información que justificaría una mayor personalización, y consecuencialmente la impersonalización es la única aproximación posible. Quizás una elección activa sea una carga innecesaria e inútil, produciendo confusión y frustración, y gastando tiempo y esfuerzos, sin mejorar sus resultados» (traducción del autor). 
por exceso; mientras que, quien sí la requiere, pagaría por la misma información, también inútil, pero ahora por defecto, de manera que es observable que los términos medios serán insuficientes para un grupo y sobreabundantes para otros, lo que crea subsidios cruzados que restan eficiencia al sistema (Ben-Shahar y Porat, 2019: 257$258,274)$. El problema, en consecuencia, no se produciría por la ineficiencia del deber de información en sí mismo, sino por la forma en la que éste se encontraría regulado (Bar-Gill, 2012: 33), sobre todo si se parte de la base de una generalización que omite los caracteres idiosincráticos de los consumidores que, hoy por hoy, pueden ser identificados por medio de big data en los términos explicados en el apartado anterior.

Ahora bien, analizando las soluciones posibles, debemos partir enunciado que transformar el deber de información en una regla completamente supletoria desmerece los propósitos vigentes de la normativa de consumo, hasta el punto en que es fácil suponer que su exclusión se transformaría en una cláusula de estilo. Sin embargo, la mayor eficiencia podría lograrse por medio de la identificación de perfiles diversos, lo que, hoy por hoy, puede conseguirse por medio del recurso al big data y a la inteligencia artificial. Si bien la diferenciación podría tomar diversas dimensiones sobre la base de los datos obtenidos, para los efectos de este trabajo sólo nos interesa aquél que se refiere a la vulnerabilidad financiera de los consumidores. Los perfiles base, en consecuencia, suponen la estratificación de los clientes a partir de comportamientos que, dependiendo de su magnitud, nos permiten apreciar un continuo que va desde la «ausencia de vulnerabilidad» a la «vulnerabilidad más extrema», ${ }^{24} \mathrm{y}$, conforme a ello, desarrollar estrategias informativas especializadas. Así, del mismo modo en que la eficacia de las reglas supletorias debe tomar en cuenta las circunstancias fácticas concretas (Porat y Strahilevitz, 2014: 1.426), una formulación imperativa de mínimos también debería construirse sobre la base de esta diversidad de perfiles. En consecuencia, desde una perspectiva económica, la eficiencia del resultado importaría que, en las circunstancias concretas de la vulnerabilidad, la información recibida por los sujetos tomaría en cuenta los antecedentes disponibles por parte de la entidad financiera, con el fin de distribuir de mejor modo los costos que importa su producción y transmisión, lo que limitaría los problemas de exceso o de defecto antes explicados.

En este sentido, el uso del big data en materia de las reglas supletorias ha sido explorado por Porat y Strhilevitz (2014) y, específicamente en la órbita del derecho de consumo, supone la posibilidad de identificar las características particulares del sujeto - a partir de la información que se posee de éste-, facilitando la propuesta de una norma que limite la necesidad de negociación. En esta fase positiva del uso del big data se supone que los proveedores ofrecerán términos contractuales ajustados a las preferencias del sujeto, incrementando la eficiencia tanto en términos microeconó-

24. Las ideas de peligrosidad y vulnerabilidad como continuo aparecen en Smith y Cooper-Martin (1997: 4). 
micos (transaccionales), como macroeconómicos (sociales) (Wagner y Eidenmüller, 2019: 582). El ejemplo propuesto es el siguiente: si bien en términos generales podría pensarse que la regla supletoria general debería ser la entrega del producto en las dependencias del vendedor, ${ }^{25}$ las características personales del sujeto podrían imponer la respuesta contraria, como ocurriría en el caso de un comprador con problemas que dificultan su desplazamiento (Porat y Strahilevitz, 2014: 1.441). Así, la norma supletoria podría construirse considerando esta característica personal y, conforme a ella, ofrecer la respuesta de la entrega en el domicilio del comprador, limitando la necesidad de negociación, aunque sin imposibilitarla. En consecuencia, la eficiencia de la norma supletoria no se observaría solo en términos generales, sobre la idea de la necesidad de alteración para la mayoría de los agentes económicos, sino ahora también en consideración de las particularidades del sujeto que se encuentran en conocimiento del proveedor. ${ }^{26}$

En el caso que nos interesa, lo anterior supondría - al menos- desdoblar el contenido de los deberes de información existentes en el contexto del mercado financiero, distinguiendo un determinado acervo sobre los «consumidores no vulnerables» y otro para quienes presentan diferentes estadios de vulnerabilidad financiera; lo que, en la lógica de la contratación en masa, solo es posible en la medida en que el proveedor pueda efectivamente ponderar los niveles de vulnerabilidad del cliente, siguiendo las formulaciones prácticas dadas por los robo-consultores y el préstamo por algoritmos ya señalados. Ahora bien, dado que en la técnica nacional el deber de información no se ofrece desde el marco de una regla dispositiva, sino imperativa de mínimos, corresponde hacer algunos ajustes a dicha formulación. Así, el mínimo dispuesto por el ordenamiento será construido en torno a un sujeto promedio, el «consumidor medio», según la articulación habitual de nuestro ordenamiento. El cambio principalmente se producirá, en consecuencia, en el aspecto en que cabe espacio a la autonomía privada, en que es esperable concluir que la persona, a pesar de no haber negociado los términos específicos de la información que requiere para un escenario puntual (por ejemplo, morosidad, sobreendeudamiento o insolvencia), la recibiría clara y en cantidad suficiente, a menos de haber expresado su voluntad de no recibirla (opt-out). En este caso, el costo de transacción supondría que el consumidor, al tiempo de la contratación, debería poder identificar dicha cláusula que le concede un derecho informativo más preciso y, luego, despreciarlo por no observar verdaderas razones para su incorporación. Ello implicaría que, si bien en términos generales el proveedor debería adecuar la información adicional a los perfiles de vulnerabilidad

25. En nuestro sistema, artículos 1.588, 1.589 y 1.825 del Código Civil.

26. Como concluye Sunstein (2014: 8), la promesa de esta personalización se encuentra en que, sin la necesidad de imponer los costos de la elección, la regla resuelve los problemas de la heterogeneidad que desconocen las normas supletorias impersonales. 
antes indicados, la aplicación específica tendría como limitación aquellos casos en los que se hubiese negociado expresamente su desestimación, entendiendo suficiente la información general que dispone el ordenamiento.

La decisión, sin embargo, puede verse alterada por la existencia $-o$ inexistenciade costos adicionales para la obtención de dicha información personalizada. ${ }^{27}$ De no existir costos relevantes, no se observan verdaderas razones para su rechazo por parte del consumidor financiero, incluso en el caso en que, al tiempo de contratar, se encuentre en un estado de bondad patrimonial. Para la justificación de una ausencia de costos, ella se desprendería de diversas variables: en primer término, el menor costo que supondría su producción y transmisión (al igual como ocurre con las «ofertas personalizadas»), en especial si se considera que, en gran medida, son los mismos insumos de información los que propician el ofrecimiento de productos o servicios financieros, que aquellos que tienden a restringirlos (especialmente, la calificación de solvencia o creditworthiness); luego, porque esta construcción también permitiría modificar el estándar de la regla imperativa, de modo de identificar de mejor modo al consumidor medio que tiene derecho a la información básica, sobre todo si se observa que la información masiva permite conocer, en mejores términos, los índices estadísticos que resultan apropiados para la formulación de un determinado estándar; y, finalmente, porque la entidad financiera tampoco tendría reales incentivos para despreciar la inclusión de la regla, en la medida en que considere su relevancia a fin de evitar escenarios en los que se haga imposible el cobro de sus créditos. ${ }^{28}$ Aunque incluso en estos casos, el contenido de la información debe estar sujeta a escrutinio. Como comprueban Bar-Gill y Warren (2008: 19-20), los servicios de asesoramiento basados en algoritmos deben ser revisados, puesto que ellos podrían no estar diseñados para la eliminación de los errores del consumidor, por ejemplo, atrayéndoles a productos que son más lucrativos para el concedente del crédito o destacando algunas características del producto financiero que resultan pueden ser más atractivas para el consumidor en búsqueda de alternativas con otros proveedores, ocultando aquellas que aún le sitúan en posición de riesgo.

Ahora bien, si la información adicional efectivamente tuviese costos que serían traspasados de forma directa al consumidor, éste sí tendría incentivos para despreciar la regla supletoria, tanto en el caso en que no avizore su necesidad (por ejemplo, por no advertir una posición económica alicaída, sea actual o potencial), como si no se encuentra en posición de soportarlos, precisamente producto de su déficit financiero. En este escenario, mantener el deber de la información adicional para el consumidor

27. Sobre el problema de los costos de la información, véase Bar-Gill (2012: 42-43).

28. Lo anterior, siempre que se superen las estrategias de sabotaje explicadas por Willis (2015: 1.321, 1.326), que, en el fondo, sugieren que el proveedor impedirá la eficacia de la información en aquellos escenarios en que le sería conveniente explotar la ignorancia del consumidor. 
vulnerable como una regla supletoria sólo tendría sentido si acaso se dispone de alguna forma de limitación, dificultando la posibilidad de exclusión (las denominadas sticky default rules, usuales en los casos en que la parte incluso ignora la existencia de la regla supletoria) (Sunstein, 2014: 6). Así, podría decirse que esta clase de reglas tienen por objeto dar una apariencia de elección, ahí donde el ordenamiento realmente no desea que éste se presente (Bubb y Pildes, 2014: 1.368), ${ }^{29} \mathrm{y}$ tienen sentido porque, aun cuando los costos de transacción para la alteración de la regla sean menores, se asume que no es frecuente que el contratante la lleve a efectos, sobre todo en la órbita del consumo (Sunstein, 2013: 6). Entonces, si se detectase una tendencia a su modificación, cabe preguntarse si el punto en debate se encuentra en una cuestión de la comparación entre los costos de la medida que pretende un mejor estándar informativo en atención a las particularidades del sujeto, o si acaso el propósito desborda el problema de tales costos y se potencia en el beneficio general que propicia su otorgamiento para los intereses de las partes y de la comunidad en general. Si así fuese, debería considerarse si en efecto debe formar parte de las políticas públicas de protección el hecho de obligar a la entidad financiera a ajustar el contenido del discurso informativo, en este caso, ante la evidencia de señales de estrés financiero, mediante reglas puramente imperativas, y no dejar espacios a la negociación sobre el punto.

Lo anterior se construye, de nuevo, desde la justificación de la tutela especial requerida, sea como mecanismo de protección de las partes del contrato (paternalismo) o de terceros ajenos (externalidades) (Wagner, 2011: 21-23). La protección será necesaria en la medida en que se pueda avizorar que el titular del mayor acervo informativo pudiese utilizarlo para su pura ventaja, lo que propiciaría una suerte de concesión abusiva de crédito fundada en los sesgos cognitivos del deudor, como los que derivan del sobreoptimismo y el espejismo de la recuperación (Pottow, 2007: 416-417). Ello al considerar, por ejemplo, la tendencia al descuento hiperbólico (Meier y Sprendeger, 2010: 195) o, más grave aún, la adicción al consumo por una porción creciente de la población, incluso bajo las fórmulas del «consumo de ostentación» (Domont-Naert, 1992: 28-30) o como «consumo compensatorio» (Caplovitz, 1967: 13), aludiendo a la función simbólica del consumo en razón de estatus o como compensación al estancamiento de la movilidad social.

Así, más allá de los riesgos de la insolvencia del deudor, el proveedor financiero podría estar apostando por una desviación de todos los flujos - propios e incluso familiares - del sujeto, de manera de impedir o retardar la agresión a su patrimonio, lo que lleva al deudor al denominado sweatbox model (Mann, 2006: 391), en que logra el cobro de una mayor tasa de interés precisamente por el estrés financiero que provoca,

29. Como señalan Ayres y Gertner (1989: 121), «cuando los costos de contratar la exclusión de una regla supletoria son muy altos, la regla supletoria empieza a parecerse a una inmutable» (traducción del autor). 
manteniendo al deudor el mayor tiempo posible en la zona próxima a la insolvencia en que tiende a efectuar pagos mínimos con el castigo que implica la elevación de la tasa aplicable. Si ya se había advertido de la explotación de la asimetría informativa y de los sesgos cognitivos por medio del mercado crediticio (Bar-Gill y Warren, 2008: 6), el problema, como advierten Wagner y Eidenmüller (2019: 594), no solo se produce por el mayor poder que genera la información acumulada por los proveedores en términos estadísticos generales, sino también en lo que respecta a la posición individual de cada uno de los sujetos respecto de los cuales posee información específica. El riesgo se exacerba, en definitiva, cuando el proveedor puede identificar, por medio de los citados algoritmos aplicados al comportamiento del sujeto, las actividades que podrían dar cuenta de una mayor propensión al consumo y a la contratación de productos o servicios inadecuados que, incluso, pueden conducir a situaciones de sobreendeudamiento. Así, detectados estos problemas, ya no hay justificación en la calificación de las reglas que establezcan deberes de consejo, advertencia y adecuación como supletorias, sino que deberían analizarse los efectos de promover normas de carácter imperativo, como se establece en el \$504(1) BGB antes referido.

\section{Un sistema de alerta frente al sobreendeudamiento del consumidor}

Finalmente, nos queda dar cuenta de los fenómenos que identificarían la mayor vulnerabilidad financiera del consumidor, y que justificarían la estratificación y la generación de señales de alerta sobre la proximidad o la presencia del sobreendeudamiento. Al efecto, a pesar de que la elaboración de un concepto unívoco de sobreendeudamiento no ha rendido aún completos frutos (Trujillo Díez, 2003: 10-14; Banco Mundial, 2013), ${ }^{30}$ sí se han elaborado ciertos parámetros generales que pueden ser utilizados a modo de generar un «sistema de alarmas» que puede ser comunicado al consumidor en sus decisiones de consumo y financiamiento que, a estas alturas, ya se encontrarán cognitivamente afectadas por la amenaza más o menos cercana de la

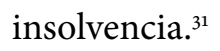

En el ordenamiento chileno, alguna referencia indirecta la encontramos en el contexto de los procedimientos concursales de renegociación, regidos por la Ley 20.720. Se trata de una respuesta concursal que presenta una fisonomía diversa a los de-

30. En cualquier caso, y ante las diferencias avizoradas entre los ordenamientos en Europa, el Dictamen del Comité Económico y Social Europeo 2014/C 311/o6 señala que la definición debe considerar: el hogar como unidad apropiada de cuantificación; los compromisos financieros e informales adquiridos; la incapacidad de pago; el sobreendeudamiento estructural; el nivel de vida digno y la insolvencia.

31. Los vestigios de la razonabilidad del sujeto se verán incluso más erosionados si, por una parte, se ha visto expuesto a los fenómenos que dan curso al sobreendeudamiento pasivo - como nuevos factores emocionales- $\mathrm{y}$, por la otra, cuando finalmente logra proyectar las dañinas consecuencias del consumo excesivo, no solo en su patrimonio, sino en su estabilidad familiar y personal. 
más procedimientos, especialmente porque su tramitación se hace ante una entidad administrativa y no judicial, como es la Superintendencia de Insolvencia y Reemprendimiento, y porque asume una menor complejidad de los activos y pasivos de la persona deudora para efectos de alcanzar una solución diversa a la mera liquidación del patrimonio embargable. Su objetivo será lograr un acuerdo entre el deudor y sus acreedores sobre la base de la transparencia de la información, sobre todo la que es presentada por el deudor (artículo 261) y, en su caso, aportada por el grupo de acreedores en forma previa o durante las diversas audiencias que contempla su sustanciación procedimental (artículos 265 a 277). Conocida la situación patrimonial, por medio de la evidencia de los activos, pasivos e ingresos de la persona deudora, los acreedores podrán calibrar aquella solución que se presente en términos más eficientes, comparando el escenario con aquel en que se produciría la liquidación de los bienes del deudor y la extinción de los saldos insolutos (artículos 255 y 268). Ahora bien, el presupuesto objetivo del procedimiento concursal de renegociación se expresa tibiamente en el artículo 260 numeral 2 de la Ley 20.720 . El ordenamiento chileno ha optado por alejarse de construcciones que estima más bien propias de las raíces del derecho mercantil (como la cesación de pagos), como a su vez a la utilización de conceptos técnicos que podrían haber motivado la necesidad de acreditación mediante un sistema probatorio más complejo, como la crisis patrimonial, el sobreendeudamiento o la insolvencia. Al efecto, a fin de objetivizar aún más tal presupuesto, dicha circunstancia se resuelve por la evidencia de tener dos o más obligaciones vencidas por más de noventa días corridos, actualmente exigibles, provenientes de obligaciones diversas, cuyo monto total sea superior a 80 unidades de fomento. Dicha opción legislativa se sustenta en la ausencia de un juicio de valor de la situación patrimonial de la persona deudora por parte de la Superintendencia de Insolvencia y Reemprendimiento, la que, carente de verdaderas facultades jurisdiccionales, resolverá el punto ante la sola evidencia del cumplimiento de dichas circunstancias objetivas.

Soportar un modelo de vulnerabilidad en el cumplimiento de los requisitos impuestos de manera legal para el inicio de un procedimiento concursal de renegociación no parece coherente con un sistema que se pretende preventivo, aun cuando no debe desmerecerse que en el núcleo de esta respuesta concursal se encuentra la pretensión de adecuar la carga financiera al perfil de ingresos reales del sujeto, sea por medio de la repactación, novación o remisión de las obligaciones (artículo 266). Más prudente parece situar el punto de partida en estados anteriores, como los que se advierte el retardo en el pago de la deuda que sustenta la realización de una primera gestión útil de cobro, o el inicio de mecanismos de cobranzas extrajudiciales, ambos en los términos fijados en el artículo 37 de la Ley 19.496, a los que ya hemos hecho referencia.

Sin embargo, también parecen ser útiles otros parámetros considerados a nivel internacional para la delimitación e identificación de supuestos de sobreendeuda- 
miento. De este modo, en el Dictamen del Comité Económico y Social Europeo sobre «El crédito y la exclusión social en la sociedad de la abundancia» (2008/C 44/19), ${ }^{32}$ se señala que

hablar de endeudamiento excesivo o de sobreendeudamiento es hacer referencia a situaciones en las que el deudor se ve en la imposibilidad, de forma duradera, de pagar el conjunto de sus deudas, o expuesto a una amenaza seria de no poder hacerles frente en el momento en que sean exigibles [...] No solo el concepto no es unívoco y su definición no está exenta de dificultades, sino que también la forma de medir el endeudamiento excesivo es fuente de divergencias. Asimismo, en otro estudio encargado por la Comisión Europea se identificaron tres fórmulas o modelos para medir el sobreendeudamiento: el modelo administrativo, el modelo subjetivo y el modelo objetivo.

Todos estos modelos son descritos en el mismo dictamen a partir del estudio encargado a OCR Macro, conocido como el «Study of the problem of Consumer Indebtedness: Statistical aspects». ${ }^{33}$

El modelo administrativo se refiere a una construcción fundada en «las estadísticas oficiales relativas a los procedimientos formales de tratamiento de estos casos», solución que requeriría someter a revisión y parametrización los datos relevantes de las personas deudoras que se han sometido a los procedimientos concursales dispuestos en la Ley 20.720 (renegociación y liquidación de bienes), con el problema que suscita el tratamiento de esos datos, todos obtenibles por medio del Boletín Concursal (Martin, 2016), y el hecho que deja fuera todos los casos en que no se ha dado inicio a un procedimiento voluntario.

El modelo subjetivo se basa en «la percepción que tienen los individuos o las familias de su solvencia financiera», de manera de revisar la propia reflexión que llevan a cabo los individuos al identificar dificultades para el pago de sus deudas. El problema se atisba desde la perspectiva de sesgos cognitivos como el sobreoptimismo, la desestimación del riesgo y el descuento hiperbólico (Goldenberg Serrano, 2017), al tiempo en que no se advierte la existencia de una fuente de información válida para su consideración. No obstante, este punto nos alerta sobre la eficacia del sistema de encuestas llevado a cabo por los robo-consultores para la identificación del perfil de los potenciales clientes, en los términos antes expresados. De lo anterior se deduce la necesidad de dirigir los cuestionarios a preguntas que no sean solo indicativas de percepciones, sino de las realidades de ingresos, gastos y activos, y que, en todo caso,

32. «Dictamen del Comité Económico y Social Europeo sobre el crédito y la exclusión social en la sociedad de la abundancia», EUR-Lex, disponible en: http://bit.ly/34xMY1Y.

33. «Study of the problem of Consumer Indebtedness: Statistical aspects», OCR Marco, disponible en https://bit.ly/38OnTTZ. 
deben ser complementados con otro tipo de datos objetivos. La propia entidad podrá considerar las estadísticas más específicas a su haber de los clientes que, en situaciones similares, llevaron a cabo ciertas conductas que a la larga resultaron inapropiadas para su bienestar financiero, y, a partir de ellas, deducir las señales de alerta que identifican a un cliente financieramente vulnerable.

De esta guisa, el modelo objetivo emplea directamente «la situación económica y financiera del agregado familiar, es decir, la relación entre la deuda total y la renta neta o entre la renta neta y el patrimonio», y parece más apropiado para efectuar valoraciones comparativas. Lo anterior no quita, como se evidencia en las enmiendas a la propuesta de Directiva del Parlamento Europeo y del Consejo sobre marcos de reestructuración preventiva, segunda oportunidad y medidas para aumentar la eficacia de los procedimientos de condonación, insolvencia y reestructuración, y por la que se modifica la Directiva 2012/30/UE, que

con el fin de lograr una mayor claridad, los Estados miembros y la Comisión deben realizar un estudio para determinar los principales indicadores del sobreendeudamiento personal. A la luz de los resultados de dicho estudio, los Estados miembros y la Comisión deben adoptar medidas por las que se establezca un sistema de herramientas de alerta rápida para el sobreendeudamiento de los consumidores. ${ }^{34}$

De lo anterior se deriva que los índices tienen componentes locales, puesto que el endeudamiento - y por ende, el sobreendeudamiento- también responde a otros factores correspondientes a la realidad nacional, como los niveles medios de ingresos, el alcance de la inclusión financiera y la cobertura de las necesidades por medio de la seguridad social, entre otros. Para estos efectos, conviene tener a la vista el análisis de las Encuestas Financieras de Hogares y las Encuestas de Protección Social, como las que presenta el Banco Central. ${ }^{35}$

\section{Conclusiones}

El dilema del sobreendeudamiento puede ser enfrentado desde diversas ópticas, entre las cuales las más usuales - aunque no por eso ajenas a críticas - son las que se estructuran sobre la base de la información que debe otorgarse al consumidor al tiempo de la contratación del crédito. Ahora bien, son tantas las dificultades que supone este modelo, en especial en lo que se refiere a la fijación de un estándar de

34. «Sobre la propuesta de Directiva del Parlamento Europeo y del Consejo sobre marcos de reestructuración preventiva, segunda oportunidad y medidas para aumentar la eficacia de los procedimientos de condonación, insolvencia y reestructuración, y por la que se modifica la Directiva 2012/30/UE», Parlamento Europeo, disponible en http://bit.ly/2sAmYWq.

35. Jaime Ruiz-Tagle, Leidy García y Álvaro Miranda, «Proceso de endeudamiento y sobreendeudamiento de los hogares en Chile». Documento 703 del Banco Central, disponible en http://bit.ly/38R285H. 
receptor medio y a las dificultades técnicas para la comprensión del mensaje, que las estrategias han ido derivando en el establecimiento de conductas más diligentes de cargo de los concedentes del crédito (el "préstamo responsable»). De este modo, la sola transmisión de información completa, clara y oportuna tiende a ser reemplazada por deberes de consejo, advertencia y adecuación, de manera que los productos y servicios financieros que sean ofrecidos a los consumidores se ajusten efectivamente a sus necesidades y perfiles de riesgo y vulnerabilidad.

Sin embargo, la asignación de esta clase de cargas y deberes a las entidades crediticias hubiese parecido tremendamente oneroso y dificultoso en las sociedades predigitales, entorpeciendo el otorgamiento del crédito y ralentizando el desarrollo económico. Pero en la actualidad estas problemáticas pueden ser solucionadas haciendo uso de las tecnologías de la información, de modo tal de generar mensajes ajustados a los parámetros de vulnerabilidad financiera que detecten proximidades al sobreendeudamiento o evidencien su existencia. Para ello, deberá reemplazarse el paradigma del consumidor medio y, a través del procesamiento de la información por medio de algoritmos, conducir al cliente específico por unas plataformas con filtros y árboles de decisión hasta la identificación de un producto financiero adecuado.

No obstante, dados los riesgos de que estas medidas sean aligeradas por el consumidor, ahí donde puedan advertirse mayores costos en la generación de estos mensajes, debería pensarse en que la misma tecnología de la información podría establecer perfiles diferenciados en la estructuración de reglas imperativas de mínimos. Pero, si el riesgo se encuentra en la conducción consciente de la entidad crediticia a productos o servicios que les permitan una mayor recaudación mediante la explotación de los sesgos financieros del sujeto (sweatbox model), esta clase de reglas debería plantearse de manera lisa y llanamente imperativas.

\section{Agradecimientos}

El presente artículo forma parte del proyecto Fondecyt Regular núm. 1180329, del cual el autor es responsable principal.

\section{Referencias}

Alarcón CAÑUta, Miguel Ángel (2018). «La deuda por obligación constituida a través de crédito con aval del Estado no constituye excepción al discharge en el ordenamiento jurídico chileno». Revista Chilena de Derecho Privado, 31: 9-59. DOI: 10.4067/So718-80722018000200009.

Andrade Ramírez, Víctor Miguel (2013). «La protección al consumidor de tarjetas de crédito: ¿Son suficientes los deberes de información?». III Congreso Estudiantil de Derecho Civil, Universidad de Chile. Disponible en https://ssrn.com/ abstract $=2349131$. 
Ausley, Amber (2019). «The prospective impact of the Global Data Protection Regegulation for entrepreneurship: A roboadvisor case study». I/S: A Journal of Law and Policy for the Information Security, 15 (1-2): 85-104. Disponible en http://bit. ly/2MjjL4P.

Ayres, Ian y Robert Gertner (1989). «Filling gaps in incomplete contracts: An economic theory of default rules». The Yale Law Journal, 99 (1): 87-130. Disponible en http://bit.ly/2PXQogb.

BANCo Mundial (2013). ResPonsible LENDING: OVERVIEW OF REGULATORY TOOLS. WASHINGTON D.C.

Baquero Herrera, Mauricio y Guillermo Caballero Germain (2013). «Artículo 17 G». En La protección de los derechos de los consumidores: Comentarios a la Ley de Protección a los Derechos de los Consumidores (pp. 449-467). Santiago: Thomson Reuters.

BAR-GILL, Oren (2012). Seduction by contract. Law, economics, and psychology in consumer markets. Oxford: Oxford University Press.

-. (2019). «Algorithmic price discrimination when demand is a function of both preferences and (mis)perceptions». The University of Chicago Law Review, 86 (2): 217-254. Disponible en https://ssrn.com/abstract $=3184533$.

BAR-GiLL, Oren y Elizabeth Warren (2008). «Making credit safer». University of Pennsylvania Law Review, 57 (1): 1-101. Disponible en http://bit.ly/2tnoA3a.

Ben-Shahar, Omri y Ariel Porat (2019). «Personalizing mandatory rules in contract law». The University of Chicago Law Review, 86 (2): 255-282. Disponible en https:// ssrn.com/abstract $=3184095$.

Ben-Shahar, Omri y Carl E. Schneider (2011). «The failure of mandated disclosure». University of Pennsylvania Law Review, 159 (3): 647-749. DOI: 10.2139/ssrn.1567284.

BRUCKNer, Matthew Adam (2018). «The promise and perils of algorithmic lenders' use of big data». Chicago-Kent Law Review, 93 (1): 3-60. Disponible en https:// ssrn.com/abstract $=3137259$.

Buвb, Ryan y Richard H. Pildes (2014). «How behavioral economics trims its sails and why». Harvard Law Review, 127 (6): 1.593-1.678. Disponible en http://bit. ly/34tobw5.

Busch, Christoph (2016). «The future of pre-contractual information duties: From behavioural insights to big data». En Christian Twigg-Flesner (editor), Research Handbook on EU Consumer and Contract Law (pp. 221-240). Cheltenham: Edward Elgar. DOI: 10.4337/9781782547372.00018.

-. (2019). «Implementing personalized law: Personalized disclosures in consumer law and data privacy law». The University of Chicago Law Review, 86 (2): 309-332. Disponible en http://bit.ly/2SoCRAb.

Caballero Germain, Guillermo (2018). «Sobreendeudamiento y exoneración legal 
de los saldos insolutos en el procedimiento concursal del consumidor». Ius et Praxis, 24 (3): 133-172. DOI: 10.4067/So718-00122018000300133.

CaPlovitz, David (1967). The poor pay more. Nueva York: MacMillan.

Degeling, Simone y Jessica Hudson (2018). «Financial robots as instruments of fiduciary duty». Sydney Law Review, 40: 63-92. Disponible en https://ssrn.com/ abstract $=3206371$.

De la Maza Gazmuri, Íñigo (2010). «El suministro de información como técnica de protección de los consumidores: Los deberes precontractuales de información». Revista de Derecho (Universidad Católica del Norte), 17 (2): 21-52. DOI: 10.4067/ So718-97532010000200002.

Domont-Naert, Françoise (1992). Consommateurs défavorisés: Crédit et endettement. Contribution á l'étude de l'efficacité du droit de la consommation. Bruselas: Kluwer Story-Scientia.

EDWARDS, Benjamin (2018). «The rise of automated finance advice: Can robo-advisers rescue the retail market?». Chicago-Kent Law Review, 93 (1): 97-112. Disponible en http://bit.ly/2 $\mathrm{M}_{3} \mathrm{KCB}$.

FinCONET (2019). DigITALISATION OF SHORT-TERM, high cost consumer credit: Guidance for supervisors. Disponible en https://bit.ly/34vfQYK.

García Porras, Catherine y William van Boom (2012). «Information disclosure in the EU Consumer Credit Directive: Opportunities and limitations». En Consumer credit, debt and investment in Europe (pp. 21-55). Cambridge: Cambridge University Press.

Gillis, Talia B. y Jann L. Spiess (2019). «Big data and discrimination». The University of Chicago Law Review, 86 (2): 459-487. Disponible en https://ssrn.com/ abstract $=3204674$.

Goldenberg Serrano, Juan Luis (2017). «El necesario ajuste de la asignación del riesgo de sobreendeudamiento en la regulación de las tarjetas de crédito: Desde un sistema basado en los deberes de información a un modelo de corresponsabilidad». Revista de Derecho (Valparaíso), 49: 55-98. DOI: 10.4067/ So718-68512017000200055.

-. (2018). «Los contornos del deber de consejo como expresión de la colaboración y como técnica de protección». Revista de Derecho (Concepción), 86 (244): 9-41. DOI: 10.4067/So718-591X2018000200009.

Jannarone, Nicole G. (2018). «Computer as confidant: Digital investment advice and the fiduciary standard». Chicago-Kent Law Review, 93 (1): 141-164. DOI: 10.31219/osf.io/8xwf6.

López DíAz, Patricia (2018). «Los supuestos y el alcance de la indemnización de daños como medio de tutela precontractual en el Código Civil chileno y su eventual confluencia con la indemnización por incumplimiento contractual». Ius et Praxis, 24 (1): 243-292. DOI: 10.4067/So718-00122018000100243. 
ManN, Ronald J. (2006). «Bankruptcy reform and the "sweat box" of credit card debt». University of Illinois Law Review, 1: 375-403. Disponible en https://ssrn. com/abstract $=895408$.

Martin, Jorge (2016). «El boletín concursal como fuente accesible al público». En Estudios de derecho comercial: Sextas jornadas chilenas de derecho comercial. Sesquicentenario de la Promulgación del Código de Comercio de la República de Chile (1865-2015) (pp. 231-241). Santiago: Ediciones UC.

MeIER, Stephan y Charles Sprendeger (2010). «Present-biased preferences and credit card borrowing». American Economic Journal: Applied Economics, 2 (1): 193-210. DOI: 10.1257/app.2.1.193.

Morrison, Stacey, Leyland Pitt y Jan Kietzmann (2015). «Technology and financial services: Marketing in times of U-Commerce». Journal of Financial Services Marketing, 20 (4): 273-281. DOI: 10.1057/fsm.2015.18.

Porat, Ariel y Lior Jacob Strahilevitz (2014). «Personalizing default rules and disclosure with big data». Michigan Law Review, 112 (8): 1.417-1.478. DOI: 10.2139/ ssrn.2217064.

Роттоw, John A. (2007). «Private liability of reckless consumer lending». University of Illinois Law Review, 1: 405-465. Disponible en https://ssrn.com/abstract=960979.

Rojas Covarrubias, Nicolás (2015). «¿Es el consumidor un mal padre de familia? Alcance del deber de cuidado exigible a los consumidores». En Estudios de derecho civil X (pp. 413-431). Santiago: Thomson Reuters.

SCHutTe, Jeanine (2017). «Using data analytics and data mining methods to determine a high net worth individual's electronic banking behaviour». Journal of Internet Banking and Commerce, 22 (3): 1-39. Disponible en http://bit.ly/36KxGZf.

ShefF, Jeremy N. (2013). «Disclosure as distribution». Washington Law Review, 88 (2): 475-49o. Disponible en https://ssrn.com/abstract $=2267627$.

Sмiтн, N. Craig y Elizabeth Cooper-Martin (1997). «Ethics and target marketing: The role of product harm and consumer vulnerability». Journal of Marketing, 61 (3): 1-20. DOI: 10.1177/002224299706100301.

Solove, Daniel J. (2013). «La autogestión de la privacidad y el dilema del consentimiento». Revista Chilena de Derecho y Tecnología, 2 (2): 11-47. DOI: 10.5354/0719-2584.2013.30308.

Sunstein, Cass (2014). «Deciding by default». University of Pennsilvania Law Review, 162 (1): 1-57. Disponible en http://bit.ly/2rXCQlP.

Trujillo DíEz, Iván Jesús (2003). El sobreendeudamiento de los consumidores. Granada: Comares.

VAndenberghe, Ann-Sophie (2011). «The role of information deficiencies in contract enforcement». En Juxtaposing autonomy and paternalism in private law (pp. 43-71). Oxford: Hart.

WAGNER, Gerhard (2011). «Mandatory contract law: Functions and principles in light 
of the proposal for a directive on consumer rights». En Juxtaposing autonomy and paternalism in private law (pp. 9-42). Oxford: Hart.

WAGNER, Gerhard y Horst Eidenmüller (2019). «Down by algorithms? Siphoning rents, exploiting biases, and shaping preferences». The University of Chicago Law Review, 86 (1): 581-609. Disponible en http://bit.ly/2PvT1Qm.

WiLlis, Lauren (2015). «Performance-based consumer law». The University of Chicago Law Review, 82.3: 1.309-1.409. Disponible en http://bit.ly/34vAIik.

\section{Sobre el autor}

Juan Luis Goldenberg Serrano es abogado. Licenciado en Derecho por la Facultad de Derecho de la Pontificia Universidad Católica de Chile. Doctor en Derecho, Universidad de Salamanca, España. Profesor asociado de la Facultad de Derecho de la Pontificia Universidad Católica de Chile. Su correo electrónico es jgoldenb@uc.cl. (iD) http://orcid.org/00oo-0003-4671-4730. 


\title{
REVISTA CHILENA DE DERECHO Y TECNOLOGÍA
}

La Revista de Chilena de Derecho y Tecnología es una publicación académica semestral del Centro de Estudios en Derecho Informático de la Facultad de Derecho de la Universidad de Chile, que tiene por objeto difundir en la comunidad jurídica los elementos necesarios para analizar y comprender los alcances y efectos que el desarrollo tecnológico y cultural han producido en la sociedad, especialmente su impacto en la ciencia jurídica.

\author{
EDITOR GENERAL \\ Daniel Álvarez Valenzuela \\ (dalvarez@derecho.uchile.cl) \\ SITIO WEB \\ rchdt.uchile.cl \\ CORREO ELECTRÓNICO \\ rchdt@derecho.uchile.cl \\ LICENCIA DE ESTE ARTÍ́CULO \\ Creative Commons Atribución Compartir Igual 4.o Internacional
}

\begin{abstract}
La edición de textos, el diseño editorial
y la conversión a formatos electrónicos de este artículo

estuvieron a cargo de Tipográfica

(www.tipografica.cl).
\end{abstract}

